\title{
STUDI BIOFISIK CALON HABITAT Manouria emys DI AREA KONSERVASI KURA-KURA DAN PENGEMBANGAN PEMBELAJARAN DI LUAR KELAS
}

\section{OJS}

\author{
Wiwit Trisnawati $^{1 *}$, Wiryono ${ }^{2}$, Bhakti Karyadi ${ }^{1}$ \\ ${ }^{1}$ Pascasarjana Pendidikan IPA FKIP Universitas Bengkulu, Bengkulu \\ ${ }^{2}$ Jurusan Kehutanan Universitas Bengkulu, Bengkulu \\ *Email: wiwittrisnawati13@gmail.com
}

\begin{abstract}
ABSTRAK
Penelitian ini bertujuan untuk mengetahui struktur dan komposisi jenis penyusun tumbuhan dan faktor abiotik (intensitas cahaya, $\mathrm{pH}$ tanah, temperatur tanah dan kelembaban udara) yang terdapat di area konservasi kura-kura Universitas Bengkulu, mengukur keterampilan proses dalam keterampilan mengobservasi, keterampilan mengukur, keterampilan mengolah data, keterampilan mengkomunikasikan dan keterampilan menginferensi, serta mengetahui paradigma siswa kelas XIPA1 SMA/MA terhadap pelestarian lingkungan melalui kegiatan pembelajaran berbasis lingkungan. Jenis penelitian ini adalah penelitian dan pengembangan yang dianalisa secara deskriptif kuantitatif. Pengembangan bahan ajar merujuk pada model pengembangan Dick dan Carey. Pada tahap pengamatan dan pengukuran vegetasi dibuat plot dengan menggunakan metode survey dan penentuan plot dengan cara purposive sampling, untuk plot ukuran 10x10m untuk tingkat pohon, 4x4m untuk tingkat perdu, 1x1m untuk tingkat herba. untuk tingkat pohon ditemukan 11 jenis, tingkat perdu 12 jenis, tingkat herba11 jenis. Indeks Nilai Penting (INP) yang tertinggi pada tingkat pohon adalah Artocarpus elasticus, tingkat perdu Stachytarpheta jamaicensis, tingkat herba Cyrtococcum patens. Indeks keanekaragaman vegetasi secara umum tergolong sedang. Prosedur penelitian di kelas dilakukan dengan langkah pembelajaran IEI dengan tahapan secara indoor, outdoor. Hasil keterampilan kinerja yang meliputi keterampilan mengobservasi, mengukur, mengolah data, mengkomunikasikan, menginferensi data secara klasikal berkategori baik, dan penilaian paradigma peserta didik yang meliputi tiga dimensi yaitu Penilaian tinggi terhadap alam, perhatian terhadap alam, Perencanaan dan bertindak hati-hati untuk menghindari resiko terhadap alam. Secara klasikal penilaian paradigma peserta didik adalah $88 \%$ berkategori baik dan $13 \%$ berkategori cukup.
\end{abstract}

Kata kunci : Manouria emys; vegetasi; keterampilan proses; paradigma; area konservasi kura-kura Universitas Bengkulu.

\section{PENDAHULUAN}

Kura-kura $M$. emys adalah jenis kura-kura darat yang memiliki ukuran tubuh paling besar di Asia (Ernst \& Das, 1989; Iskandar, 2000, Schaffer \& Morgan, 2002). Ciri utamanya adalah tidak dijumpainya selaput renang pada jari tengah dan kaki, ciri ini menandakan bahwa kura-kura ini bersifat teresterial atau penghuni daratan (Lambert \& Howes, 1994, Abou-Madi \& Jacobson, 2003, Heiss et al. 2011, Hoogmoed \& Crumly,1984). Menurut Iskandar (2000) makanan kura-kura ini terutama terdiri dari daun- daunan (kangkung, talas), buah-buahan dan akarakaran. Jenis kura-kura ini hidup pada hutan primer daratan rendah sampai pada ketinggian 1000 meter dpl dan umumnya dijumpai pada hutan primer yang berbukit-bukit (Liat \& Das, 1999 dalam Kurniati dan Buiiding, 2007). IUCN tahun 2014 menyatakan bahwa kura-kura ini termasuk dalam daftar merah (red list) dengan kategori genting (Croyle et al. 2016)

Universitas Bengkulu merupakan salah satu lembaga yang sangat mendukung program kegiatan konservasi terhadap sumber daya alam hayati. Salah satunya seperti yang dilakukan oleh program studi pascasarjana (S2) pendidikan IPA 
Fakultas Keguruan dan dan Ilmu Pendidikan (FKIP) yang menjadikan kampus Universitas Bengkulu yang hijau dan banyak terdapat kolam, bisa dijadikan sebagai "rumah aman" bagi perkembangan spesies kura-kura, sampai saat ini sudah ada 3 wilayah ekosistem kolam yang dimanfaatkan oleh mahasiswa pascasarjana (S2) Pendidikan IPA Fakultas Keguruan dan dan Ilmu Pendidikan (FKIP) sebagai wilayah konservasi kura-kura. Wilayah tersebut meliputi taman konservasi yang berada di samping gedung rektorat dan gedung bersama 1, taman pintar yang berada di depan gedung dekanat FKIP dan area konservasi pendipa di dekat gedung pascasarjana (S2) Pendidikan IPA Universitas Bengkulu. Program konservasi tersebut dilakukan dalam upaya melestarikan hewan kurakura Sumatra yang hampir punah. kegiatan konservasi ini dijadikan sarana penelitian dan pendidikan untuk mahasiswa Universitas Bengkulu dan para siswa pada jenjang pendidikan dasar dan menengah (Wiryono, 2009)

Program "Unib Campus, a Safe Home for Turtles" dapat berlangsung optimal, apabila sikap bertanggung jawab terhadap konservasi ex-situ kura kura Sumatera ditanamkan sedini mungkin melalui pendidikan formal atau informal pada jenjang pendidikan dasar dan menengah. Pendidikan konservasi dengan pendekatan lingkungan sekitar (pembelajaran di luar kelas) diharapkan dapat membangun pengetahuan dan paradigma serta perilaku siswa terhadap lingkungan, sehingga diharapkan siswa dapat bersikap ilmiah terhadap alam, kemudian mampu menerapkan dalam kehidupan seharihari, selain itu pendidikan konservasi merupakan salah satu factor penting untuk meminimalisir kerusakan lingkungan hidup dan merupakan sarana penting dalam menghasilkan sumber daya manusia yang dapat melaksanakan prinsip pembangunan berkelanjutan.

Pendidikan konservasi sangatlah penting diterapkan di lingkungan pendidikan, khususnya pada siswa SMA, karena diharapkan dengan pendidikan konservasi ini membuat siswa mendapatkan informasi berdasarkan pengalaman langsung, mengenal dan mencintai lingkungan yang pada akhirnya mengagumi dan mengangungkan penciptanya, dan membuat siswa bisa menjaga dan memanfaatkan lingkungan dengan baik dan benar tanpa harus merusaknya. Berlatar belakang masalah di atas maka perlu dilakukan penelitian tentang Studi habitat $M$. emys di area konservasi kura-kura Universitas Bengkulu dan pengembangan perangkat pembelajaran di luar kelas untuk mengetahui paradigma siswa SMA tentang pelestarian lingkungan.

\section{METODE PENELITIAN}

Penelitian ini dilaksanakan pada bulan Februari sampai bulan Maret 2017 di area konservasi kura-kura Universitas Bengkulu dan pada bulan April di kelas X IPA 1 MAN 1 Model kota Bengkulu. Penelitian ini menggunakan metode survey dengan penentuan plot secara sengaja (purposive sampling) dengan ukuran $10 \mathrm{~m} \times 10 \mathrm{~m}$ untuk tingkat pohon, $4 \mathrm{~m} \times 4 \mathrm{~m}$ untuk tingkat perdu, dan $1 \mathrm{~m} \times 1 \mathrm{~m}$ untuk tingkat herba. Plot pengamatan dibuat sebanyak 5 plot di sekitar lokasi penelitian di area konservasi kurakura M. emys Universitas Bengkulu.

\section{Prosedur Penelitian}

Untuk mengidentifikasi vegetasi yang terdapat di area konservasi kura-kura $M$. emys Universitas Bengkulu di buat plot dengan menggunakan metode survey dan penentuan plot dengan cara purposive sampling, untuk plot ukuran $10 \times 10 \mathrm{~m}$ untuk tingkat pohon, $4 \times 4 \mathrm{~m}$ untuk tingkat perdu, $1 \times 1 \mathrm{~m}$ untuk tingkat herba, sebanyak 5 plot. Prosedur penelitian dilakukan dengan model IEI dengan secara indoor, outdoor, indoor. Penelitian indoor dilaksanakan di kelas dan penelitian outdoor di laksanakan di area konservasi kura-kura UNIB. Penilaian yang dilakukan meliputi penilaian keterampilan kinerja dan penilaian paradigma peserta didik terhadap lingkungan.

\section{Teknik Analisa Data}

Data dianalisis setelah diketahui nama latin dari jenis tumbuhan tersebut dengan menggunakan persamaan :

$$
\begin{aligned}
& \text { - } \operatorname{Kerapatan}(\mathrm{K})=\frac{\text { Jumlah Individu }}{\text { Luas Plot }} \\
& \text { Kerapatan Relatif }(\mathrm{KR})= \\
& \frac{\text { Kerapatan suatu jenis }}{\text { Kerapatan total seluruh jenis }} \times 100 \%
\end{aligned}
$$


- $\quad$ Frekuensi $(\mathrm{F})=$ Jumlah petak ditemukan suatu jenis Jumlah seluruh petak

- $\quad$ Frekuensi Relatif (FR) = $\frac{\text { Frekuensi suatu jenis }}{\text { Frekuensi total seluruh jenis }} \times 100 \%$

- Dominansi (D) = Luas bidang dasar suatu spesies

Luas petak contoh

Dominansi Relatif (DR) $=$ $\frac{\text { Dominasi Suatu Jenis }}{\text { Dominasi Total Seluruh Jenis }} \times 100 \%$

- $\quad$ Luas Bidang Dasar $($ LBD $)=1 / 4 \pi \mathrm{d}^{2}$

- Indeks Nilai Penting (INP) untuk pohon $=\mathrm{KR}$ $+\mathrm{FR}+\mathrm{DR}$

- Indeks Nilai Penting (INP) untuk perdu dan herba $=\mathrm{KR}+\mathrm{FR}$

- Keanekaragaman pohon

Untuk menghitung keanekaragaman pohon, digunakan indeks keanekaragaman ShannonWienner dengan rumus sebagai berikut:

$$
H^{\prime}=\sum_{i=1}^{S} P i \ln P i
$$

dimana

$\mathrm{H}=$ Indeks keanekaragaman Indeks

$P i=$ ni $/ \mathrm{N}$

$\mathrm{Ni}=$ Jumlah individu jenis ke $\mathrm{i}$

$\mathrm{N}=$ Jumlah individu semua jenis

Mueller-Dombois dan Ellenberg 1974, dalam Wiryono et al, 2016

\section{HASIL DAN PEMBAHASAN}

Hasil penelitian yang telah dikelompokkan dalam tumbuhan tingkat pohon, perdu, dan herba yang terdapat di area calon habitat konservasi kura-kura Universitas Bengkulu disajikan dalam Tabel 1, Tabel 2, dan Tabel 3 berikut.

Tabel 1. Klasifikasi spesies tumbuhan tingkat pohon yang ditemukan di area konservasi kurakura M. emys Universitas Bengkulu

\begin{tabular}{|l|l|l|l|l|}
\hline Kelas & Ordo & Famili & \multicolumn{1}{|c|}{ Jenis } & \multicolumn{1}{|c|}{$\begin{array}{c}\text { Nama } \\
\text { Daerah }\end{array}$} \\
\hline $\begin{array}{l}\text { Magno } \\
\text { liopsid } \\
\text { a }\end{array}$ & $\begin{array}{l}\text { Sapinda } \\
\text { les }\end{array}$ & $\begin{array}{l}\text { Burserac } \\
\text { eae }\end{array}$ & $\begin{array}{l}\text { Protium } \\
\text { javanicum }\end{array}$ & Bawang \\
\cline { 2 - 5 } & $\begin{array}{l}\text { Laurale } \\
\text { s }\end{array}$ & $\begin{array}{l}\text { Lauracea } \\
\text { e }\end{array}$ & $\begin{array}{l}\text { Cinnamomun } \\
\text { porrectum }\end{array}$ & $\begin{array}{l}\text { Kayu } \\
\text { Gadis }\end{array}$ \\
\cline { 2 - 5 } & \multirow{2}{*}{$\begin{array}{l}\text { Euphor } \\
\text { biales }\end{array}$} & \multirow{2}{*}{$\begin{array}{l}\text { Euphorbi } \\
\text { aceae }\end{array}$} & $\begin{array}{l}\text { Bridelia } \\
\text { tomentosa }\end{array}$ & Keniday \\
\cline { 4 - 5 } & \multirow{2}{*}{$\begin{array}{l}\text { Mallotus } \\
\text { paniculatus }\end{array}$} & $\begin{array}{l}\text { Balik } \\
\text { Angin }\end{array}$ \\
\cline { 3 - 5 } & & & Aporosa & Pelangas \\
\hline
\end{tabular}

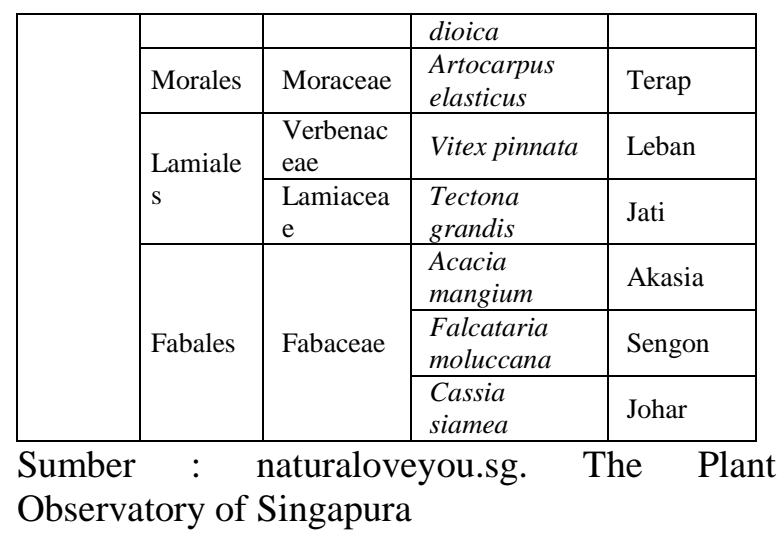

Tabel 2. Klasifikasi spesies tumbuhan tingkat perdu yang ditemukan di area konservasi kurakura M. emys Universitas Bengkulu.

\begin{tabular}{|c|c|c|c|c|}
\hline Kelas & Ordo & Famili & Jenis & $\begin{array}{c}\text { Nama } \\
\text { Daerah }\end{array}$ \\
\hline \multirow{12}{*}{$\begin{array}{l}\text { Magno } \\
\text { liopsid } \\
\text { a }\end{array}$} & \multirow{2}{*}{ Fabales } & \multirow{2}{*}{ Fabaceae } & $\begin{array}{l}\text { Acacia } \\
\text { mangium }\end{array}$ & Akasia \\
\hline & & & $\begin{array}{l}\text { Archidendron } \\
\text { jiringa }\end{array}$ & Jengkol \\
\hline & \multirow{2}{*}{$\begin{array}{l}\text { Myrtal } \\
\text { es }\end{array}$} & $\begin{array}{l}\text { Melastoma } \\
\text { ceae }\end{array}$ & $\begin{array}{l}\text { Melastoma } \\
\text { malabathricu } \\
m\end{array}$ & Seduduk \\
\hline & & $\begin{array}{l}\text { Combretac } \\
\text { eae }\end{array}$ & $\begin{array}{l}\text { Terminalia } \\
\text { catappa }\end{array}$ & Ketaping \\
\hline & \multirow{3}{*}{$\begin{array}{l}\text { Lamial } \\
\text { es }\end{array}$} & \multirow{3}{*}{$\begin{array}{l}\text { Verbenace } \\
\text { ae }\end{array}$} & $\begin{array}{l}\text { Lantana } \\
\text { camara }\end{array}$ & $\begin{array}{l}\text { Temblek } \\
\text { an }\end{array}$ \\
\hline & & & $\begin{array}{l}\text { Stachytarphet } \\
\text { a jamaicensis }\end{array}$ & $\begin{array}{l}\text { Pecut } \\
\text { kuda }\end{array}$ \\
\hline & & & Vitex pinnata & Leban \\
\hline & Rutales & Meliaceae & $\begin{array}{l}\text { Azadirachta } \\
\text { indica }\end{array}$ & Mimba \\
\hline & \multirow{2}{*}{$\begin{array}{l}\text { Morale } \\
\text { s }\end{array}$} & \multirow[t]{2}{*}{ Moraceae } & $\begin{array}{l}\text { Artocarpus } \\
\text { elasticus }\end{array}$ & Terap \\
\hline & & & Ficus hispida & Ara \\
\hline & $\begin{array}{l}\text { Ericale } \\
\mathrm{s}\end{array}$ & $\begin{array}{l}\text { Myrsinace } \\
\text { ae }\end{array}$ & $\begin{array}{l}\text { Ardisia } \\
\text { elliptica }\end{array}$ & $\begin{array}{l}\text { Rempena } \\
\mathrm{i}\end{array}$ \\
\hline & $\begin{array}{l}\text { Sapind } \\
\text { ales }\end{array}$ & $\begin{array}{l}\text { Anacardiac } \\
\text { eae }\end{array}$ & $\begin{array}{l}\text { Mangifera } \\
\text { indica }\end{array}$ & Mangga \\
\hline
\end{tabular}

Sumber : naturaloveyou.sg. The Plant Observatory of Singapura

Tabel 3. Klasifikasi spesies tumbuhan tingkat herba yang ditemukan di area konservasi kurakura M. emys Universitas Bengkulu.

\begin{tabular}{|c|l|l|l|l|}
\hline Kelas & Ordo & Famili & \multicolumn{1}{|c|}{ Jenis } & $\begin{array}{c}\text { Nama } \\
\text { Daerah }\end{array}$ \\
\hline $\begin{array}{c}\text { Magno } \\
\text { liopsid } \\
\text { a }\end{array}$ & $\begin{array}{l}\text { Crophu } \\
\text { lariales }\end{array}$ & $\begin{array}{l}\text { Acanthac } \\
\text { eae }\end{array}$ & $\begin{array}{l}\text { Asystasia } \\
\text { gangetica }\end{array}$ & $\begin{array}{l}\text { Rumput } \\
\text { Israel }\end{array}$ \\
\cline { 2 - 5 } & $\begin{array}{l}\text { Gerani } \\
\text { ales }\end{array}$ & $\begin{array}{l}\text { Oxalidac } \\
\text { eae }\end{array}$ & $\begin{array}{l}\text { Oxalis } \\
\text { barrelieri }\end{array}$ & $\begin{array}{l}\text { Belimbin } \\
\text { g Tanah }\end{array}$ \\
\cline { 2 - 5 } & Fabales & Fabaceae & $\begin{array}{l}\text { Centrosema } \\
\text { molle }\end{array}$ & $\begin{array}{l}\text { Kembang } \\
\text { telang }\end{array}$ \\
\cline { 3 - 5 } & & $\begin{array}{l}\text { Mimosa } \\
\text { diplotricha }\end{array}$ & $\begin{array}{l}\text { Putri } \\
\text { malu }\end{array}$ \\
\cline { 2 - 5 } & Gentia & $\begin{array}{l}\text { Rubiacea } \\
\text { e }\end{array}$ & $\begin{array}{l}\text { Richardia } \\
\text { scabra }\end{array}$ & \\
\cline { 2 - 5 } & Asteral & $\begin{array}{l}\text { Asteracea } \\
\text { e }\end{array}$ & $\begin{array}{l}\text { Mikania } \\
\text { micrantha }\end{array}$ & $\begin{array}{l}\text { Rambata } \\
\text { n }\end{array}$ \\
\hline
\end{tabular}




\begin{tabular}{|l|l|l|l|l|}
\hline & & & $\begin{array}{l}\text { Sphagneticola } \\
\text { trilobata }\end{array}$ & $\begin{array}{l}\text { Matahari } \\
\text { kecil }\end{array}$ \\
\cline { 2 - 5 } & $\begin{array}{l}\text { Diosco } \\
\text { reales }\end{array}$ & $\begin{array}{l}\text { Dioscore } \\
\text { aeae }\end{array}$ & $\begin{array}{l}\text { Discorea } \\
\text { hispida }\end{array}$ & Gadung \\
\hline $\begin{array}{l}\text { Liliops } \\
\text { ida }\end{array}$ & Poales & Poaceae & $\begin{array}{l}\text { Cyrtococcum } \\
\text { patens }\end{array}$ & $\begin{array}{l}\text { Rumput } \\
\text { Papaitan }\end{array}$ \\
\hline $\begin{array}{l}\text { Pterido } \\
\text { psida }\end{array}$ & $\begin{array}{l}\text { Blechn } \\
\text { ales }\end{array}$ & $\begin{array}{l}\text { Blechnac } \\
\text { eae }\end{array}$ & $\begin{array}{l}\text { Stenochlaena } \\
\text { palustris }\end{array}$ & $\begin{array}{l}\text { Paku } \\
\text { merah }\end{array}$ \\
\hline & $\begin{array}{l}\text { Gleich } \\
\text { eniales }\end{array}$ & $\begin{array}{l}\text { Gleichen } \\
\text { aceae }\end{array}$ & $\begin{array}{l}\text { Gleichenia } \\
\text { linearis }\end{array}$ & $\begin{array}{l}\text { Paku } \\
\text { resam }\end{array}$ \\
\hline
\end{tabular}

Sumber : naturaloveyou.sg. The Plant Observatory of Singapura

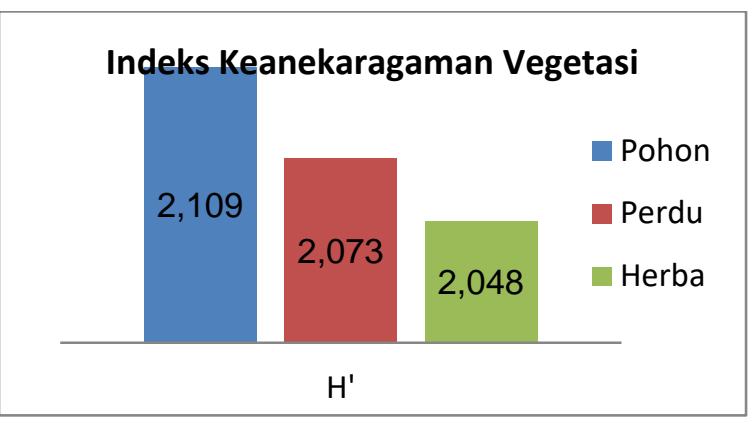

Gambar 1. Grafik Indeks Keragaman Vegetasi

Nilai indeks keanekaragaman untuk pohon sebesar 2,109, indeks keanekaragaman untuk perdu 2,073 dan indeks keanekargaman untuk herba adalah 2,048 Nilai tersebut menunjukkan bahwa keanekaragaman jenis pohon, perdu dan herba di area konservasi kura-kura M. emys Universitas Bengkulu tersebut tergolong sedang.

Tabel 4. Nilai kriteria apek penilaian keterampilan secara klasikal

\begin{tabular}{|c|l|c|c|}
\hline No & $\begin{array}{c}\text { Aspek Keterampilan } \\
\text { Kinerja }\end{array}$ & $\begin{array}{c}\text { Rata-rata } \\
\text { setiap } \\
\text { kelompok }\end{array}$ & Kriteria \\
\hline 1 & Mengobservasi & 75 & Baik \\
\hline 2 & Mengukur & 85 & Baik \\
\hline 3 & Mengolah Data & 75 & Baik \\
\hline 4 & Mengkomunikasikan & 77 & Baik \\
\hline 5 & Menginferensi & 75 & Baik \\
\hline
\end{tabular}

Secara klasikal keterampilan kinerja dapat dilihat dari tabel di atas yaitu pada aspek mengobservasi, mengukur, mengolah data, mengkomunikasikan dan menginferensi didapatkan kriteri baik.

Berdasarkan kisi-kisi paradigma terhadap lingkungan yang terdapat diinstrumen terdapat tiga dimensi yaitu dimensi penilaian tinggi terhadap alam, perhatian terhadap alam dan merencanakan dan bertindak hati-hati untuk menghindari resiko terhadap alam. Pada dimensi paradigma lingkungan yang pertama yaitu Penilaian tinggi terhadap alam skor persentase yang didapatkan peserta didik adalah 68,75\% berkriteria baik, dan $31,25 \%$ berkriteria sangat baik.

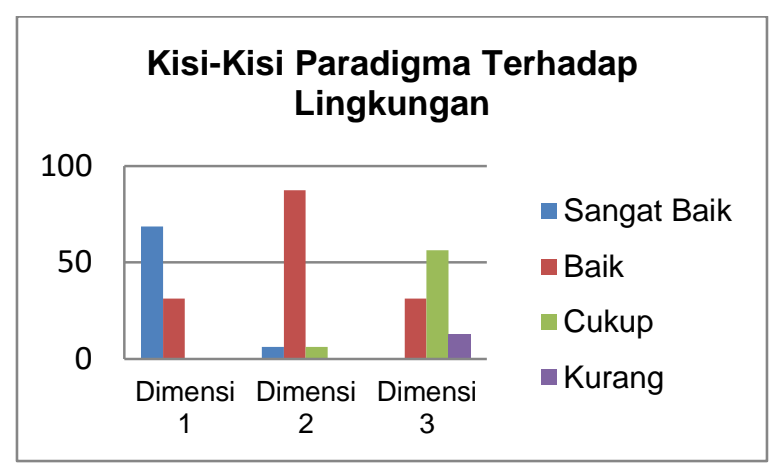

Gambar 2. Grafik Hasil Penilaian Kisi-kisi Paradigma Terhadap Lingkungan.

Dimensi paradigma terhadap lingkungan yang kedua adalah perhatian tinggi terhadap alam, skor persentase yang didapatkan peserta didik adalah $6,25 \%$ untuk kriteria sangat baik, $87,5 \%$ berkriteria baik dan $6,25 \%$ untuk kriteria cukup.

Dimensi paradigma terhadap lingkungan yang ketiga adalah Merencanakan dan bertindak hati-hati untuk menghindari resiko terhadap alam, skor persentase yang didapatkan peserta didik adalah $31,25 \%$ untuk kriteria baik, $56,25 \%$ berkriteria cukup dan $12,5 \%$ untuk kriteria kurang.

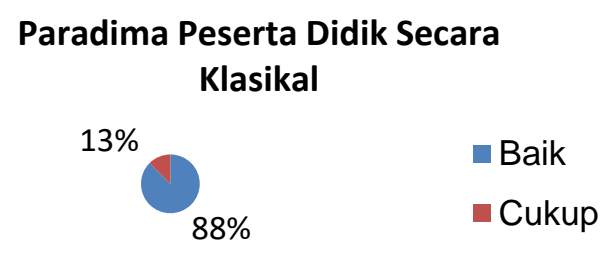

Gambar 3: Grafik Paradigma Pesera Didik Secara Klasikal

Secara klasikal berdasarkan hasil instrumen yang diberikan ke masing-masing peserta didik, didapatkan hasil $87,5 \%$ dengan kriteria baik, hal ini menunjukkan bahwa sebagian besar peserta didik memiliki pandangan yang baik terhadap pelestarian lingkungan, dan $12,5 \%$ dengan kriteria cukup hal ini menunjukkan bahwa 
peserta didik sebagian kecil memiliki pandangan yang cukup terhadap pelestarian lingkungan.

Peserta didik juga sudah memiliki pandangan bahwa dengan menjaga dan melestarikan lingkungan dapat meminimalisir kerusakan terhadap lingkungan dan sebagai upaya untuk meningkatkan pemahaman dan kepedulian peserta didik dalam mencari pemecahan dan pencegah timbulnya masalah terhadap lingkungan.

\section{KESIMPULAN}

Berdasarkan penelitian yang telah dilakukan dapat disimpulkan bahwa Nilai indeks keanekaragaman untuk pohon sebesar 2,109, indeks keanekaragaman untuk perdu 2,073 dan indeks keanekargaman untuk herba adalah 2,048 Nilai tersebut menunjukkan bahwa keanekaragaman jenis pohon, perdu dan herba di area konservasi kura-kura $M$. emys Universitas Bengkulu tersebut tergolong sedang.

Berdasarkan kisi-kisi paradigma terhadap lingkungan yang terdapat diinstrumen terdapat tiga dimensi yaitu dimensi penilaian tinggi terhadap alam, perhatian terhadap alam dan merencanakan dan bertindak hati-hati untuk menghindari resiko terhadap alam. Pada dimensi paradigma lingkungan yang pertama yaitu Penilaian tinggi terhadap alam skor persentase yang didapatkan peserta didik adalah 68,75\% berkriteria baik, dan $31,25 \%$ berkriteria sangat baik. Dimensi paradigma terhadap lingkungan yang kedua adalah perhatian tinggi terhadap alam, skor persentase yang didapatkan peserta didik adalah $6,25 \%$ untuk kriteria sangat baik, $87,5 \%$ berkriteria baik dan $6,25 \%$ untuk kriteria cukup. Dimensi paradigma terhadap lingkungan yang ketiga adalah Merencanakan dan bertindak hati-hati untuk menghindari resiko terhadap alam, skor persentase yang didapatkan peserta didik adalah $31,25 \%$ untuk kriteria baik, $56,25 \%$ berkriteria cukup dan $12,5 \%$ untuk kriteria kurang.

\section{DAFTAR PUSTAKA}

Abou-Madi, N., \& Jacobson, E. R. (2003). Effects of blood processing techniques on sodium and potassium values: a comparison between Aldabra tortoises (Geochelone gigantea) and Burmese mountain tortoises (Manouria emys). Veterinary clinical pathology, 32(2), 61-66.

Croyle, K., Gibbons, P., Light, C., Goode, E., Durrant, B., \& Jensen, T. (2016). Chelonian perivitelline membrane-bound sperm detection: A new breeding management tool. Zoo biology, 35(2), 95-103.

Heiss, E., Natchev, N., Schwaha, T., Salaberger, D., Lemell, P., Beisser, C., \& Weisgram, J. (2011). Oropharyngeal morphology in the basal tortoise Manouria emys emys with comments on form and function of the testudinid tongue. Journal of morphology, 272(10), 1217-1229.

Hoogmoed, M. S., \& Crumly, C. R. (1984). Land tortoise types in the Rijksmuseum van Natuurlijke Historie with comments on nomenclature and systematic (Reptilia: Testudines: Testudinidae). Zoologische Mededelingen, 58(15), 241-259.

Iskandar, D. T. (2000). Kura-kura dan buaya Indonesia dan Papua Nugini. Jurusan Biologi, Fakultas Matematika dan Ilmu Pengetahuan Alam, Institut Teknologi Bandung.

Kurniati, H., \& Buiiding, W. (2007). The herpetofauna of the gold mining project area in North Sumatra: species richness before exploitation activities. Zoo Indonesia, Jurnal Fauna Tropika, 16, 1-11.

Lambert, F. R., \& Howes, J. R. (1994). Ranging, breeding behaviour and food of the Asian brown tortoise Manouria emys in Borneo. Malayan Nature Journal (Malaysia).

Schaffer, C., \& Morgan, V. (2002). Behavioral observations of captive juvenile Manouria emys phayrei with notes on degrees of intergradation with Manouria emys emys. Turtle and Tortoise Newsletter, 5, 26.

Wiryono. (2009). Ekologi Hutan.Unib Press. Bengkulu

Wiryono. Alif YZ, Yemi. (2016). Modul Pendidikan Konservasi Kura-kura Sumatra Sekolah Menengah Atas. Unit Penerbit FKIP. UNIB Bengkulu 